\title{
High Positive End-Expiratory Pressure During High-Frequency Jet Ventilation Improves Oxygenation and Ventilation in Preterm Lambs
}

\author{
GABRIELLE C. MUSK, GRAEME R. POLGLASE, J. BERT BUNNELL, CARRYN J. MCLEAN, ILIAS NITSOS, YONG SONG, \\ AND J. JANE PILLOW \\ School of Women's and Infants' Health [G.C.M., G.R.P., C.J.M., I.N., Y.S., J.J.P.], University of Western Australia, Perth, Western \\ Australia 6009, Australia; Bunnell Inc [J.B.B.], Salt Lake City, Utah 84115
}

\begin{abstract}
Increasing positive end-expiratory pressure (PEEP) is advocated to recruit alveoli during high-frequency jet ventilation (HFJV), but its effect on cardiopulmonary physiology and lung injury is poorly documented. We hypothesized that high PEEP would recruit alveoli and reduce lung injury but compromise pulmonary blood flow (PBF). Preterm lambs of anesthetized ewes were instrumented, intubated, and delivered by cesarean section after instillation of surfactant. HFJV was commenced with a PEEP of $5 \mathrm{~cm} \mathrm{H}_{2} \mathrm{O}$. Lambs were allocated randomly at delivery to remain on constant PEEP ( $\mathrm{PEEP}_{\text {const }}, n=6$ ) or to recruitment via stepwise adjustments in PEEP ( $\mathrm{PEEP}_{\mathrm{adj}}, n=6$ ) to $12 \mathrm{~cm} \mathrm{H}_{2} \mathrm{O}$ then back to $8 \mathrm{~cm} \mathrm{H}_{2} \mathrm{O}$ over the initial $60 \mathrm{~min}$. PBF was measured continuously while ventilatory parameters and arterial blood gases were measured at intervals. At postmortem, in situ pressure-volume deflation curves were recorded, and bronchoalveolar lavage fluid and lung tissue were obtained to assess inflammation. PEEP ${ }_{\text {adj }}$ lambs had lower pressure amplitude, fractional inspired oxygen concentration, oxygenation index, and PBF and more compliant lungs. Inflammatory markers were lower in the PEEP $_{\text {adj }}$ group. Adjusted PEEP during HFJV improves oxygenation and lung compliance and reduces ventilator requirements despite reducing pulmonary perfusion. (Pediatr Res 69: 319-324, 2011)
\end{abstract}

$\mathrm{H}$ igh-frequency ventilation (HFV) is advocated as a lung protective ventilation strategy for the treatment of respiratory distress syndrome (RDS) in preterm newborn infants. HFV has proven particularly useful for optimizing lung volume, reducing atelectotrauma and volutrauma, and therefore reducing injurious lung stimuli associated with bronchopulmonary dysplasia (BPD) (1-3). High-frequency jet ventilation (HFJV) and high-frequency oscillatory ventilation (HFOV) are the two main forms of HFV used in NICUs, and although there is substantial research on the optimal approach to lung volume optimization in preterm RDS using HFOV, data are limited for HFJV. To date, there is one multicenter controlled trial and one single-center controlled trial comparing the use of HFJV [with a low positive end-expiratory

Received September 8, 2010; accepted October 30, 2010.

Correspondence: Gabrielle C. Musk, Senior Lecturer in Veterinary Anaesthesia School of Veterinary and Biomedical Sciences, Murdoch University, South Street, Murdoch, WA 6150, Australia; e-mail: g.musk@murdoch.edu.au

Supported by the Women and Infants Research Foundation, an Ada Bartholomew Medical Research Trust grant, Bunnell Inc. (unrestricted research grant), a NHFA/ NHMRC Fellowship [G.R.P.], and a Viertel Senior Medical Research Fellowship [J.J.P.]. pressure (PEEP) strategy] to conventional mechanical ventilation (CMV) for treatment of preterm RDS $(4,5)$. The results give conflicting information regarding the respiratory and neurological outcomes of neonates treated with HFJV. Increased adverse neurological outcomes for HFJV group in the study by Wiswell et al. (5) were attributed to hypocarbia (6). Subgroup analysis in the trial by Keszler et al. (4) suggested that the use of low PEEP was associated with an increased risk for grade III-IV intraventricular hemorrhage or periventricular leukomalacia. An important limitation of these trials is that the HFJV groups were not compared with a true "lung protective" CMV strategy. Further research assessing the pros and cons of optimized versus low PEEP in HFJV is therefore warranted.

HFJV is characterized by a (normally) fixed brief inspiratory time, passive expiration, and coupling with a conventional ventilator for provision of conventional breaths, PEEP, and bias flow. The current strategy recommended for treatment of RDS with HFJV is to commence HFJV early in the disease process with a peak inspiratory pressure (PIP) just below that being used during CMV (Bunnell Inc, HOW to use the LifePulse HFV: Seven Steps to Success, available at http://www. bunl.com/Clinical\%20PDFs/New\%20How\%20to\%20use\%20 the \%20LifePulse\%20New\%2012-09.pdf; accessed October 12, 2010). The initial PEEP is set to achieve a mean airway pressure $\left(P_{\mathrm{aw}}\right)$ equal to that used before commencement of HFJV. The primary method advocated for optimizing lung volume recruitment in HFJV is by incrementing PEEP until stable peripheral

\footnotetext{
Abbreviations: ABP, arterial blood pressure; BAL, bronchoalveolar lavage; CMV, conventional mechanical ventilation; CTGF, connective tissue growth factor; $\mathbf{F i O}_{2}$, fractional inspired oxygen concentration; $\mathbf{H F J V}$, high-frequency jet ventilation; HFOV, high-frequency oscillatory ventilation; HFV, high-frequency ventilation; MPO, myeloperoxidase; OI, oxygenation index; $\mathbf{P a C O}_{2}$, partial pressure of $\mathrm{CO}_{2}$ in arterial blood; $\mathbf{P a O}_{2}$, partial pressure of oxygen in arterial blood; PAP, pulmonary artery blood pressure; $P_{\text {aw }}$, mean airway pressure; PBF, pulmonary blood flow; PEEP, positive end-expiratory pressure; $\mathbf{P E E P}_{\text {adj }}$, adjusted PEEP strategy (PEEP commenced at $5 \mathrm{~cm} \mathrm{H}_{2} \mathrm{O}$ with stepwise increments to 12 $\mathrm{cm} \mathrm{H}_{2} \mathrm{O}$ over $20 \mathrm{~min}$, then decremented to $8 \mathrm{~cm} \mathrm{H}_{2} \mathrm{O}$ in two steps by $60 \mathrm{~min}$, where it remained until study completion at $2 \mathrm{~h}$ ); $\mathbf{P E E P}$ const. $_{\text {, constant PEEP }}$ strategy (PEEP remained at $5 \mathrm{~cm} \mathrm{H}_{2} \mathrm{O}$ for the duration of the 2-h study); PIP, peak inspiratory pressure; RDS, respiratory distress syndrome; $\mathbf{S p O}_{2}$, peripheral oxyhemoglobin saturation measured by a pulse oximeter; $\Delta P$, delta $P$ [pressure differential (PIP - PEEP)]; UVC, unventilated control
} 
oxyhemoglobin saturation $\left(\mathrm{SpO}_{2}\right)$ is achieved, with low-rate CMV breaths added to HFJV as a supplementary method for recruiting collapsed alveoli (algorithm provided by Bunnell Inc, Finding Optimal PEEP during HFV, available at http://www. bunl.com/Patient\%20Management/OptimalPEEP.pdf; accessed October 12, 2010).

Despite the detailed guidelines provided for optimizing lung volume during initiation of HFJV, the evidence basis for this approach is limited. Although inadequate PEEP will encourage airway collapse and atelectasis and initiate the lung injury sequence, excessive PEEP promotes alveolar overdistension, impedes pulmonary perfusion, decreases venous return, and depresses cardiovascular function (7-9).

We hypothesized that a PEEP-driven lung volume recruitment protocol would enhance arterial oxygenation and ventilation without promoting lung injury during the initiation of ventilation in a preterm ovine model of RDS. Furthermore, we hypothesized that these effects would be achieved at the expense of pulmonary perfusion. We aimed to compare the effect of an adjusted PEEP strategy on pulmonary blood flow (PBF), blood gases, and lung injury with a constant low PEEP strategy in an instrumented preterm lamb model.

\section{MATERIALS AND METHODS}

All animal procedures were approved by the University of Western Australia animal ethics committee, according to the guidelines of the National Health and Medical Research Council of Australia code of practice for the care and use of animals for scientific purposes.

Animals, instrumentation, and delivery. Single and twin-bearing datemated merino ewes were anesthetized at $128-130 \mathrm{~d}$ gestation (term is $\sim 150$ d) with intramuscular xylazine $\left(0.5 \mathrm{mg} \cdot \mathrm{kg}^{-1}\right.$; Troy Laboratories, New South Wales, Australia) and ketamine $\left(20 \mathrm{mg} \cdot \mathrm{kg}^{-1}\right.$; Parnell Laboratories, New South Wales, Australia) and intubated with a $7.5-\mathrm{mm}$ cuffed tracheal tube (Portex Ltd., England). Maternal anesthesia was maintained with halothane in $100 \% \mathrm{O}_{2}$. The fetus was exteriorized, and a right lateral thoracotomy was performed. A flow probe (4R; Transonic Systems, Ithaca, NY) was positioned around the left pulmonary artery, and a catheter was inserted into the main pulmonary artery (7). The fetus was intubated orally (4.5-mm cuffed tracheal tube; Portex Ltd.), lung fluid was suctioned, and intratracheal surfactant (100 $\mathrm{mg} \cdot \mathrm{kg}^{-1}$ : Survanta, $25 \mathrm{mg}$ of phospholipids $\mathrm{mL}^{-1}$; Abbott Laboratories, IL) was administered before cesarean section delivery of the lamb. Unventilated controls (UVCs; $n=6$ ) were euthanized (pentobarbitone, $100 \mathrm{mg} \cdot \mathrm{kg}^{-1}$ i.v.) at delivery without instrumentation.

Postnatal care. Instrumented lambs were dried, weighed, and randomized to one of two ventilation groups: constant PEEP (PEEP const $\left._{2} n=6\right)$ and adjusted PEEP (PEEP $\left.{ }_{\text {adj }} ; n=6\right)$. They were commenced on HFJV according to a predetermined protocol (Fig. 1). Umbilical venous and arterial catheters were inserted. Propofol $(0.1 \mathrm{mg} / \mathrm{kg} / \mathrm{min}$; Repose $10 \%$, Norbrook Laboratories Ltd., Victoria, Australia) and remifentanil $(0.05 \mu \mathrm{g} / \mathrm{kg} / \mathrm{min}$; Ultiva, Abbott Laboratories) were infused continuously through an umbilical vein for anesthesia and analgesia. An umbilical arterial catheter was used for continuous measurement of systemic arterial blood pressure (ABP) and intermittent sampling to assess gas exchange and acid-base balance. Rectal temperature was monitored continuously and maintained between 38 and $39^{\circ} \mathrm{C}$ (normothermic for newborn lambs).

The Oxygenation Index (OI) was calculated as OI $=\frac{\mathrm{FiO}_{2} \times \mathrm{P}_{\mathrm{aw}} \times 100}{\mathrm{PaO}_{2}}$, where $\mathrm{FiO}_{2}$ is fractional inspired oxygen concentration, $P_{\text {aw }}$ is mean airway pressure, and $\mathrm{PaO}_{2}$ is $\mathrm{PO}_{2}$ in arterial blood.

High-frequency jet ventilation. HFJV (Life Pulse High-Frequency Ventilator; Bunnell Inc., Salt Lake City, Utah) coupled to a pressure-limited time-cycled infant conventional ventilator (BP 200 Infant Pressure Ventilator; Bourns Life Systems, CA) was commenced immediately following delivery. HFJV was commenced using a respiratory rate of 420 breaths per minute ( 7 $\mathrm{Hz}$ ) and PIP of $40 \mathrm{~cm} \mathrm{H}_{2} \mathrm{O}$. HFJV PIP was adjusted to a maximum of $40 \mathrm{~cm}$ $\mathrm{H}_{2} \mathrm{O}$ to target moderate permissive hypercapnia $\left(\mathrm{PCO}_{2}\right.$ in arterial blood $\left(\mathrm{PaCO}_{2}\right) 45-55 \mathrm{~mm} \mathrm{Hg}$ ). The initial $\mathrm{FiO}_{2}$ of 0.4 was adjusted to maintain $\mathrm{SpO}_{2}$

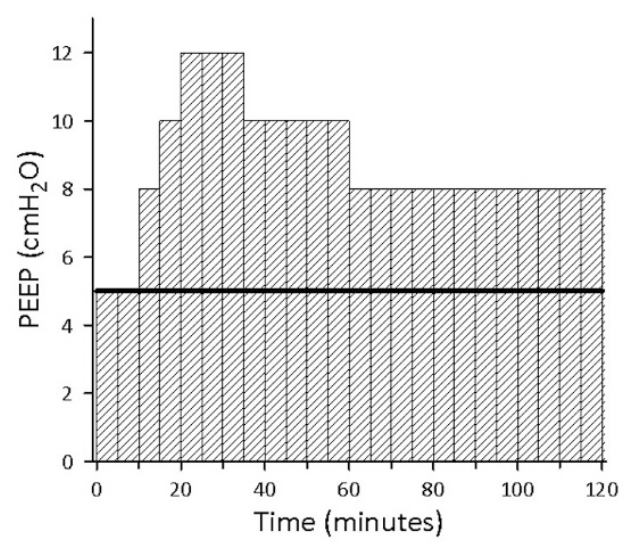

Figure 1. Constant and adjusted PEEP protocols. Lambs were ventilated at either a constant PEEP of $5 \mathrm{~cm} \mathrm{H}_{2} \mathrm{O}$ ( $\mathrm{PEEP}_{\text {const }}$, solid line) or with stepwise increments and decrements to PEEP ( PEEP $_{\text {adj }}$, gray). Values are mean (SEM).

of $90-95 \%$. Inspiratory time $\left(t_{\mathrm{I}}\right)$ was fixed at $0.02 \mathrm{~s}$. No conventional ventilator breaths were applied during the 2-h study period.

PEEP was maintained at $5 \mathrm{~cm} \mathrm{H}_{2} \mathrm{O}$ in the $\mathrm{PEEP}_{\text {const }}$ group for the duration of the study. Lambs in the PEEP adj group were stabilized on a PEEP of $5 \mathrm{~cm}$ $\mathrm{H}_{2} \mathrm{O}$ for 10 min then PEEP was incremented at $10 \mathrm{~min}\left(8 \mathrm{~cm} \mathrm{H}_{2} \mathrm{O}\right), 15 \mathrm{~min}$ $\left(10 \mathrm{~cm} \mathrm{H}_{2} \mathrm{O}\right)$, and $20 \mathrm{~min}\left(12 \mathrm{~cm} \mathrm{H}_{2} \mathrm{O}\right)$. PEEP was decreased by $2 \mathrm{~cm} \mathrm{H}_{2} \mathrm{O}$ at $35 \mathrm{~min}$ and $60 \mathrm{~min}$ and then maintained at $8 \mathrm{~cm} \mathrm{H}_{2} \mathrm{O}$ from 60 min until euthanasia at $120 \mathrm{~min}$.

Continuous measurements of PBF, pulmonary artery blood pressure (PAP), and systemic ABP were processed via calibrated pressure transducers (Maxxim Medical, TX). Data were amplified and stored on a digital data acquisition system (Powerlab 8SP; ADInstruments, New South Wales). Pulmonary wave form analysis was performed at regular time points as described previously (10). Pulsatility Index, a measure of downstream resistance to blood flow, was calculated as (peak systolic flow - minimum flow after diastolic flow)/mean peak systolic flow over five consecutive cardiac cycles.

Tidal volume $\left(V_{\mathrm{T}}\right)$ was measured continuously using an electronic flowmeter (Florian, Acutronics, CH). Ventilator settings (respiratory rate, PIP, PEEP, $P_{\text {aw }}$, delta $P(\Delta P)$, servo pressure, and $\left.t_{\mathrm{i}}\right)$ were recorded at intervals. After final measurements were obtained, the $\mathrm{FiO}_{2}$ was increased to 1.0 for 2 min, the tracheal tube was occluded for $3 \mathrm{~min}$, and the lamb was euthanized (100 $\mathrm{mg} \cdot \mathrm{kg}^{-1}$ pentobarbitone i.v.).

Postmortem. The lung was exposed by thoracotomy, and an in situ deflation pressure volume curve was obtained (11). The right upper lung lobe was inflation fixed $\left(30 \mathrm{~cm} \mathrm{H}_{2} \mathrm{O}\right)$ in formalin and samples of the right lower lobe were snap frozen for molecular analyses. Bronchoalveolar lavage (BAL) was performed on the left lung for cytology and protein analysis by the Lowry method. Differential cell counts were performed on cytospin samples of the BAL fluid stained with Diff-Quik (Fronine Lab Supplies, New South Wales, Australia).

Total RNA was isolated from $30 \mathrm{mg}$ of homogenized lung tissue using the RNeasy Mini kit (Qiagen, USA) according to the manufacturer's instructions. The contaminating genomic DNA was removed by an on-column DNaseI digestion performed using the DNaseI digestion kit (Qiagen). One microgram of RNA was then reverse transcribed into cDNA in a $20-\mu \mathrm{L}$ reaction with QuantiTect Reverse Transcription Kit (Qiagen). The primers used for amplifying IL $1 \beta$, IL-6 (12) and IL-8, early growth response (EGR) 1 , connective tissue growth factor (CTGF), and cysteine rich 61 (CYR 61) were described previously (13). Amplification and detection of specific products were conducted on the Rotor-gene 3000 real-time PCR system (Corbett Life Science) with the published cycle profiles using Rotor-gene SYBR Green PCR Kit (Qiagen) following the manufacturer's instructions. The expression levels of genes of interest were normalized into 18S RNA (14) using the $2^{-\Delta \Delta C T}$ method (15) and presented as expression ratio relative to the UVC group.

Myeloperoxidase (MPO) activity was measured spectrophotometrically using methods described by Faith et al. in 2008 (16) and McCabe et al. in 2001 (17). The MPO activity was normalized to the total protein content of the tested samples. Activity was expressed as units of MPO activity per milligram of protein, where one unit of MPO was defined as the amount needed to degrade 1 $\mu \mathrm{mol}$ of hydrogen peroxide per minute at room temperature.

Statistical analyses. For comparison of two groups of ventilated animals at specific time points, a Mann-Whitney rank-sum test (nonparametric data) or a $t$ test (parametric data) was used. Comparisons of two ventilated groups against the UVCs used one-way ANOVA. A two-way repeated measure ANOVA was used to determine the effect of PEEP on PBF and Pulsatility 
Table 1. Baseline characteristics

\begin{tabular}{lccc}
\hline & UVC & PEEP $_{\text {const }}$ & PEEP $_{\text {adj }}$ \\
\hline$n$ (male) & $6(3)$ & $6(4)$ & $6(4)$ \\
Twin (singleton) & $4(2)$ & $6(0)$ & $6(0)$ \\
Birthweight* $(\mathrm{kg})_{\mathrm{GA}^{*}(\mathrm{~d})}$ & $2.9(0.4)$ & $3(0.3)$ & $2.8(0.2)$ \\
Cord $^{*}$ & $127.2(0.4)$ & $128(0.8)$ & $128(0.8)$ \\
Cord PaCO $_{2}^{*}(\mathrm{~mm} \mathrm{Hg})$ & $7.15(0.1)$ & $7.15(0.05)$ & $7.09(0.1)$ \\
\hline
\end{tabular}

* Values are expressed as mean (SEM).

Index and the effect of time on PIP, $\Delta P, P_{\text {aw }}$, and servo pressure. Data in the text and legends are expressed as mean (SEM) or median (25th percentile, 75th percentile) unless otherwise stated. Analyses were performed using SigmaStat (version 3.5; Systat Software Inc, Chicago, IL), with $p<0.05$ considered statistically significant.

\section{RESULTS}

Baseline characteristics of lambs in each group were not different (Table 1).

Ventilator settings and lung mechanics. Changes in $P_{\text {aw }}$ reflected the different PEEP protocols (Fig. 2A) but as PIP decreased in both groups, $\Delta P$ also decreased (Fig. $2 B$ ). The $V_{\mathrm{T}}$ was higher in PEEP adj group (pooled time points: $p<0.01$ ) despite a significantly lower $\Delta P$ (Fig. 2C). Servo pressure was lower $(p=0.026)$ in the PEEP $_{\text {adj }}$ group at $120 \mathrm{~min}$ (Table 2). Pressure-volume curves showed a higher volume achieved per unit of pressure for the $\mathrm{PEEP}_{\mathrm{adj}}$ lambs compared with the $\operatorname{PEEP}_{\text {const }}$ lambs $\left(p=0.003\right.$ at $\left.40 \mathrm{~cm} \mathrm{H}_{2} \mathrm{O}\right)$ and for both of the ventilated groups compared with the UVCs (Fig. 2D).

Oxygenation. The target $\mathrm{SpO}_{2}$ of $90-95 \%$ was achieved in both groups within the first $10 \mathrm{~min}$ and was maintained throughout the ventilation period. $\mathrm{FiO}_{2}$ and OI were lower in the $\mathrm{PEEP}_{\text {adj }}$ group compared with the $\mathrm{PEEP}_{\text {const }}$ lambs from 45 min until the end of the ventilation period (Fig. $3 A$ and $B$ ).

Blood gases. The target $\mathrm{PaCO}_{2}$ was achieved within $10 \mathrm{~min}$ in both groups and was maintained between 45 and $55 \mathrm{~mm} \mathrm{Hg}$ throughout the ventilation procedure (Table 2). The $\mathrm{pH}$, arterial lactate concentration, and base excess (BE) were comparable between the two groups for the duration of the ventilation period (Table 2).

Hemodynamic consequences of different PEEP protocols. PBF increased over the first 10 min of ventilation in both groups, and there were no significant differences between the groups at any time point between 10 and $120 \mathrm{~min}$. PBF decreased by $\sim 8 \%$ in the PEEP $_{\text {const }}$ group and by $\sim 48 \%$ in the $\mathrm{PEEP}_{\text {adj }}$ group between 10 and $120 \mathrm{~min}(p=0.507$ and $p=$ 0.026 , respectively; Fig. $4 A$ ). After an initial decrease during the transition from fetal to neonatal circulation, the Pulsatility Index increased in both groups over time and was significantly higher in the PEEP $_{\text {adj }}$ group over much of the first 60 min (Fig. $4 B)$. The pulmonary and systemic ABPs were not different between the groups at any time point (Table 2). End-diastolic and end-systolic PBFs were significantly decreased at $15 \mathrm{~min}$ in the $\mathrm{PEEP}_{\text {adj }}$ group ( $p<0.001$ for each parameter). For all pulmonary artery variables, the difference between PEEP $_{\text {const }}$ and PEEP ${ }_{\text {adj }}$ was temporary (Fig. $4 C$ and $D$ ).

Lung injury. BAL fluid protein concentration was higher in ventilated groups than in the UVCs, but no difference between

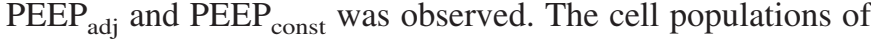
BAL fluid did not differ between the groups (Table 3).

In lung tissue, the expression of IL- $1 \beta$, IL-6, IL-8, CTGF, and EGR1 mRNA was increased in the PEEP $_{\text {const }}$ group compared with UVCs, whereas CYR 61 expression was significantly increased in the PEEP ${ }_{\text {adj }}$ group compared with UVCs. The expression of IL-1 $\beta$, IL-6, EGR1, and CTGF was greater in the $\mathrm{PEEP}_{\text {const }}$ group compared with PEEP adj. There was no difference in MPO activity (Table 3 ) between each of the three groups.

\section{DISCUSSION}

Alveolar recruitment during HFJV can be achieved by delivering CMV breaths or adjusting PEEP, or both. To examine the role of PEEP for alveolar recruitment during HFJV, this study aimed to compare the effect of an adjusted versus a constant PEEP protocol on oxygenation, ventilation, pulmonary hemodynamics, and lung injury during HFJV. We showed that lambs in the PEEP $_{\text {adj }}$ group had better oxygenation and lung compliance but decreased PBF compared with $\mathrm{PEEP}_{\text {const }}$ lambs. Markers of lung injury were higher in the PEEP $_{\text {const }}$ group in this short-term study.

The correlation between $P_{\mathrm{aw}}$ and oxygenation during HFJV is well understood. As expected by study design, the $P_{\text {aw }}$ of the $\mathrm{PEEP}_{\text {adj }}$ group was significantly higher than the PEEP $\mathrm{Ponst}_{\text {group }}$ throughout the ventilation period. The benefit of higher $P_{\text {aw }}$ was evidenced by lower $\mathrm{FiO}_{2}$ requirements from as early as $45 \mathrm{~min}$, supporting the concept that a high $P_{\text {aw }}$ strategy enhances arterial oxygenation, decreasing the $\mathrm{FiO}_{2}$ required during ventilation (18). In a clinical setting, PEEP is increased and $\mathrm{FiO}_{2}$ is decreased until the $\mathrm{SpO}_{2}$ or $\mathrm{PaO}_{2}$ plateaus or falls. When $\mathrm{FiO}_{2}$ is stable at 0.21, optimal PEEP has been achieved (19). The OI describes the relationship between $\mathrm{FiO}_{2}, P_{\text {aw }}$, and $\mathrm{PaO}_{2}$ : a lower value implies better arterial oxygenation (20). After the initial decrease in OI within the $\mathrm{PEEP}_{\text {const }}$ group, the OI increased over the remainder of the study. In the $\mathrm{PEEP}_{\text {adj }}$ group, it remained relatively low and stable despite the higher $P_{\mathrm{aw}}$, suggesting more efficient gas exchange due to either airway stenting or increased gas-exchange surface due to effective volume recruitment.

Servo pressure is the automatically controlled driving pressure of the ventilator and changes in response to altered monitored airway pressure to ensure that the ventilator will continue to deliver inspiratory gas to meet the set PIP (21). Servo pressure increases as PIP increases, with increased lung and/or chest wall compliance, a decrease in airway resistance, or if there is an air-leak or circuit disconnection. A decrease in servo pressure however, indicates either a reduction in set PIP, or worsening compliance and increased resistance to gas flow, obstruction of the tracheal tube, tension pneumothorax, and the requirement for suctioning or right mainstem bronchus intubation (www.bunl. com/ServoSlidesNEW.html). Our finding of a lower servo pressure throughout most of the study period in PEEP $_{\text {adj }}$ lambs, despite evidence of increased lung compliance, likely reflects the reductions in PIP required to maintain moderate permissive hypercapnia and to avoid overventilation.

The hemodynamic consequences of the ventilation protocol were assessed by measurement of PBF, PAP, systemic ABP, pulse rate, and calculation of Pulsatility Index. Pulsatility Index is 
A

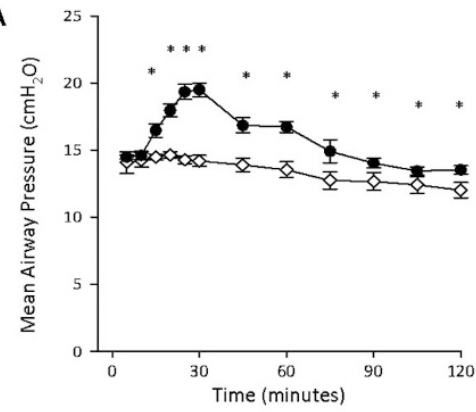

C

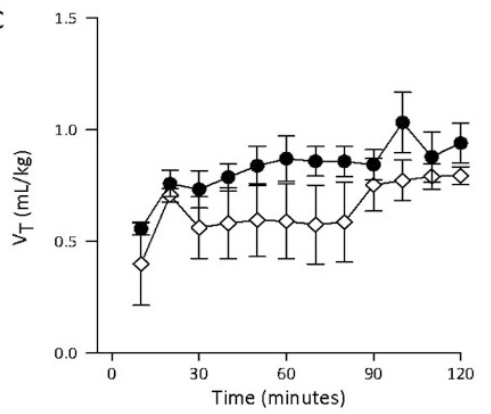

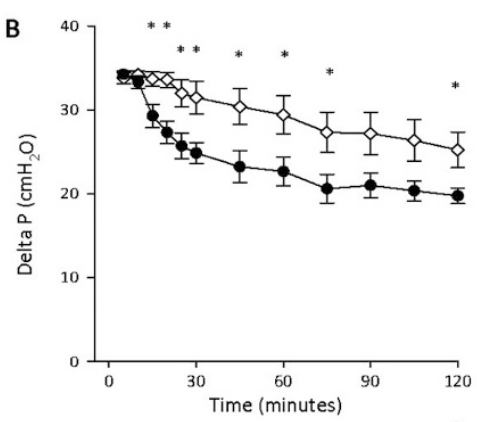

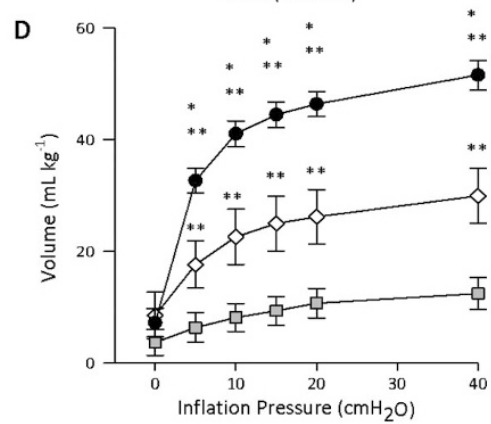

Figure 2. Ventilator settings and lung mechanics. $(A)$ Mean airway pressure $\left(P_{\text {aw }}\right),(B)$ delta $P$ $(\Delta P),(C)$ tidal volume, and $(D)$ deflation limb of the postmortem in situ pressure-volume curves. $\diamond, \mathrm{PEEP}_{\text {const }} ; \bigcirc, \mathrm{PEEP}_{\text {adj }} ; \square$, unventilated control. $* p<0.05$ compared with PEEP $_{\text {const }}$ and $* * p<0.05$ compared with unventilated control. Values are mean (SEM).

Table 2. Cardiovascular and respiratory physiological measurements

\begin{tabular}{|c|c|c|c|c|c|c|}
\hline \multirow[b]{2}{*}{ Time } & \multicolumn{3}{|c|}{ PEEP $_{\text {const. }}$} & \multicolumn{3}{|c|}{ PEEP $_{\text {adj }}$} \\
\hline & $10 \mathrm{~min}$ & $60 \mathrm{~min}$ & $120 \mathrm{~min}$ & $10 \mathrm{~min}$ & $60 \mathrm{~min}$ & $120 \mathrm{~min}$ \\
\hline PIP $\left(\mathrm{cmH}_{2} \mathrm{O}\right)$ & $40(0)$ & $34.5(2.5)$ & $30.2(2.3)$ & $40(0)$ & $32.8(1.9)$ & $27.9(1)$ \\
\hline$P_{\text {aw }}\left(\mathrm{cmH}_{2} \mathrm{O}\right)$ & $14.1(0.9)$ & $13.5(0.6)$ & $12(0.6)$ & $14.5(0.2)$ & $16.7(0.4)^{*}$ & $13.5(0.3)^{*}$ \\
\hline Servo pressure (psi) & $6.6(0.8)$ & $8.3(0.3)$ & $7(0.3)$ & $7.8(0.4)$ & $6.8(0.7)$ & $5.9(0.3)^{*}$ \\
\hline $\mathrm{PaCO}_{2}(\mathrm{mmHg})$ & $52.0(4.6)$ & $41.5(2)$ & $43.3(2.6)$ & $39.8(3.4)$ & $38.2(3.5)$ & $41.4(3.1)$ \\
\hline $\mathrm{pH}$ & $7.1(0.1)$ & $7.4(0.02)$ & $7.4(0.04)$ & $7.3(0.1)$ & $7.3(0.04)$ & $7.4(0.03)$ \\
\hline Lactate $\left(\mathrm{mg} \cdot \mathrm{dL}^{-1}\right)$ & $83.9(13.4)$ & $67.4(10.7)$ & $48.1(10.9)$ & $87.2(22.6)$ & $67.2(19)$ & $50.4(20.1)$ \\
\hline Base Excess & $-8.8(2.1)$ & $-2.2(1.4)$ & $-0.9(2.1)$ & $-6.8(3.2)$ & $-5.4(1.9)$ & $-1.5(2.2)$ \\
\hline Left PAP (mm Hg) & $43.6(4.3)$ & $35.6(3.8)$ & $43.2(6.8)$ & $48.5(1.6)$ & $37.4(3.4)$ & $43.8(5.6)$ \\
\hline Systemic ABP $(\mathrm{mm} \mathrm{Hg})$ & $53.5(6.2)$ & $50.1(4.4)$ & $60.3(6.7)$ & $53(3.2)$ & $50.2(3.1)$ & $53.3(3.4)$ \\
\hline Pulse rate (bpm) & $140(7)$ & $170(15)$ & $194(8) \ddagger$ & $145(8)$ & $181(15)$ & $210(8) \ddagger$ \\
\hline
\end{tabular}

Values are expressed as mean (SEM).

$* p<0.05$ PEEP $_{\text {adj }}$ compared with PEEP const $_{\text {a }}$ at the same time.

$\dagger p<0.001$ time 120 compared with time 10 in the same group.

psi, pounds per square inch; bpm, beats per minute.
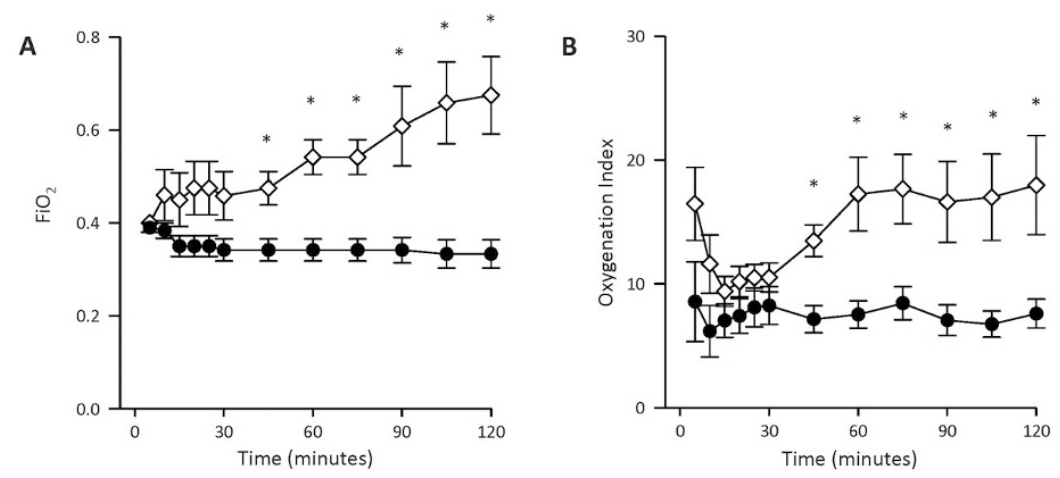

Figure 3. Oxygenation. (A) $\mathrm{FiO}_{2},(B)$ OI over the 120 -min ventilation period. $\diamond, \mathrm{PEEP}_{\text {const }} ;$ PEEP $_{\text {adj. }} * p<0.05$ compared with PEEP const . Values are mean (SEM). directly related to resistance to blood flow. An increase in intrathoracic pressure during any kind of positive pressure ventilation impacts on venous return, cardiac output, right ventricular end-diastolic volume, PBF, and pulmonary vascular resistance (22). Increased PEEP reduces PBF during conventional ventilation of very premature lambs by increasing pulmonary vascular resistance (PVR) (8). A similar decrease in PBF in response to $P_{\text {aw }}$-driven alveolar recruitment maneuvers during HFOV of up to $69.3 \%$ is also reported (7). Importantly, during HFOV, the fall in PBF persisted after $P_{\text {aw }}$ was decreased following recruitment (7). The mechanism causing a fall in PBF as PEEP (and consequently also $P_{\text {aw }}$ ) is increased may include an increase in the 

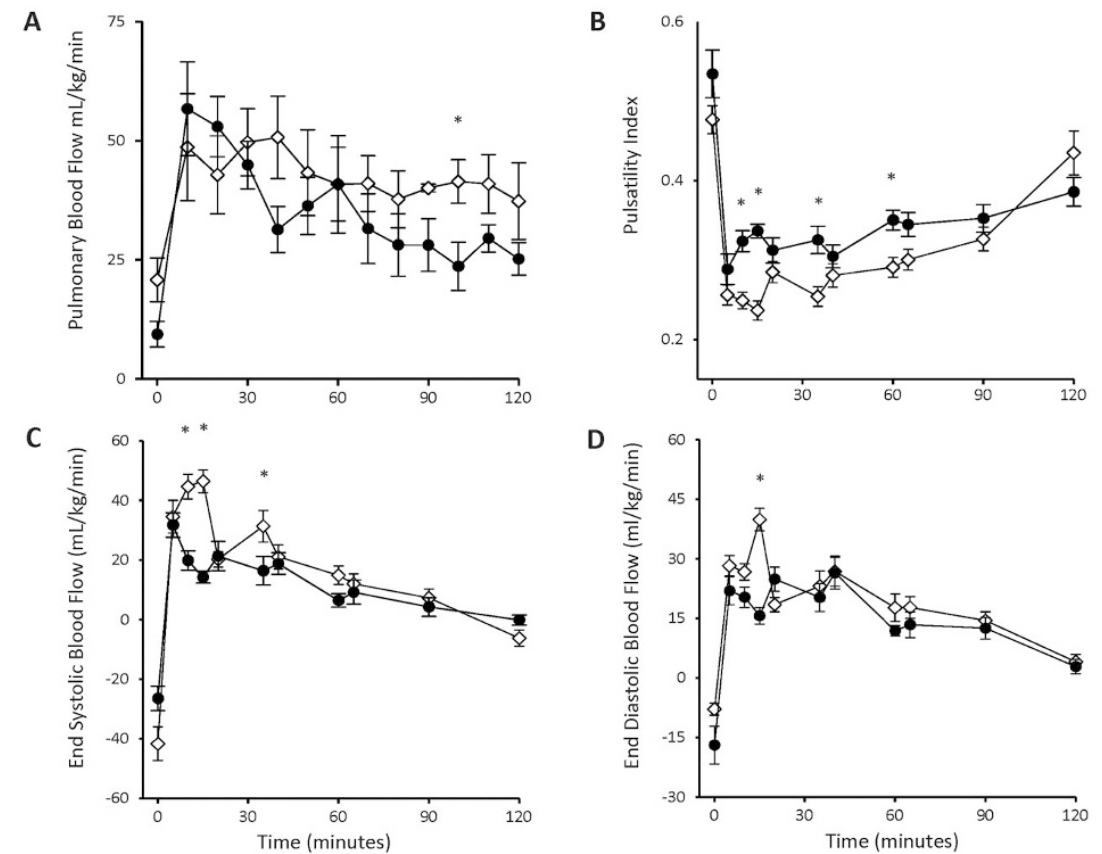

Figure 4. Pulmonary perfusion. (A) $\mathrm{PBF},(B)$ Pulsatility Index over the 120-min ventilation period, $(C)$ End-diastolic blood flow, $(D)$ Endsystolic blood flow. $\diamond, \mathrm{PEEP}_{\text {const }} ; \boldsymbol{\bullet}, \mathrm{PEEP}_{\text {adj }}$. $* p<0.05$ compared with PEEP ${ }_{\text {adj }}$ and $* * p<$ 0.05 time 120 min compared with time $10 \mathrm{~min}$. Values are mean (SEM).

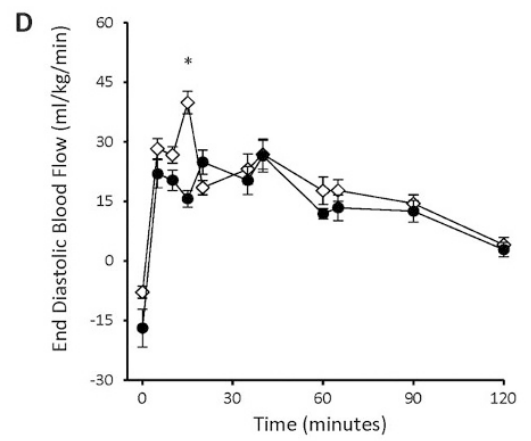

Table 3. Postmortem inflammatory markers

\begin{tabular}{|c|c|c|c|}
\hline & UVC & PEEP $_{\text {const }}$ & PEEP $_{\text {adj }}$ \\
\hline \multicolumn{4}{|l|}{ BAL fluid } \\
\hline Protein concentration $\left(\mathrm{mg} \mathrm{mL}^{-1}\right)$ & $14.7(7.4)$ & $120.2(28)^{*}$ & $89.2(18.5)^{*}$ \\
\hline Inflammatory cells $\left(\times 10^{3} \mathrm{~kg}^{-1}\right)$ & $0.3(0.02)$ & $7.5(3.9)^{*}$ & $2.0(1.0)$ \\
\hline Neutrophils $\left(\times 10^{3} \mathrm{~kg}^{-1}\right)$ & 0 & $4.4(2.4)$ & $0.4(0.2)$ \\
\hline Mononuclear cells $\left(\times 10^{3} \mathrm{~kg}^{-1}\right)$ & $0.3(0.02)$ & $2.7(1.4)^{*}$ & $1.5(0.8)$ \\
\hline Lymphocytes $\left(\times 10^{3} \mathrm{~kg}^{-1}\right)$ & 0 & $0.4(0.3)$ & $0.1(0.1)$ \\
\hline \multicolumn{4}{|l|}{ Lung tissue } \\
\hline IL- $1 \beta$ fold change & $0.6(0.4,3.2)$ & $262.9(159.3,350) \ddagger$ & $37.2(18.2,53.7) \ddagger$ \\
\hline IL-6 fold change & $1.0(0.6,1.6)$ & $95.5(57.2,155.4)^{*}$ & $13.4(3.2,23.8) \ddagger$ \\
\hline IL-8 fold change & $0.7(0.6,2.0)$ & $77.6(26.1,101.1) \ddagger$ & $28.0(6.3,53.9)$ \\
\hline EGR1 fold change & $1.1(0.3,2.9)$ & $48.9(33.5,94.7)^{*}$ & $15.6(5.4,27.1) \ddagger$ \\
\hline CTGF fold change & $0.8(0.6,2.4)$ & $31.2(13.3,44.3)^{*}$ & $4.0(1.97,5.9) \ddagger$ \\
\hline CYR61 fold change & $0.9(0.7,1.3)$ & $9.7(5.4,20.1)$ & $11.0(5.9,12.2)^{*}$ \\
\hline MPO activity§ & $18.2(1.4)$ & $29.3(3.8)$ & $26.6(6.1)$ \\
\hline
\end{tabular}

Values are expressed as mean (SEM) or median (25th percentile, 75 th percentile).

$* p<0.05$ compared with UVC.

$\dagger p<0.001$ compared with UVC.

$\$ p<0.05$ compared with PEEP const.

$\S$ Units per milligrams of protein where 1 unit of MPO is defined as the amount needed to degrade $1 \mu$ mol of hydrogen peroxide per minute at room temperature.

alveolar capillary transmural pressure causing capillary compression $(8,23)$. The noncompliant immature lung may be less susceptible to capillary compression than a mature lung $(8,23)$. Factors that increase lung compliance (e.g. antenatal corticosteroids, exogenous surfactant, and lung volume recruitment) may increase the sensitivity of PBF to changes in airway pressure (23). We observed previously that incrementing PEEP to $12 \mathrm{~cm}$ $\mathrm{H}_{2} \mathrm{O}$ during conventional ventilation improved oxygenation at the expense of PBF (8). Improved oxygenation at the expense of PBF was also observed previously using an incremental $P_{\text {aw }}$ strategy during HFOV (7).

The fall in PBF in the $\mathrm{PEEP}_{\text {adj }}$ group reversed rapidly as PEEP was initially decreased, suggesting the impact of a PEEP recruitment strategy on PBF during HFJV was not sustained. Further- more, the impact of increased PEEP on end-diastolic and endsystolic blood flows coincided with the initial increase in PEEP from 5 to $8 \mathrm{~cm} \mathrm{H}_{2} \mathrm{O}$ at $10 \mathrm{~min}$. The difference between the two groups was temporary, and despite further increases in PEEP in the $\mathrm{PEEP}_{\text {adj }}$ group, the blood flow variables did not remain significantly different. The maintenance of a higher $P_{\text {aw }}$ in the $\mathrm{PEEP}_{\text {adj }}$ group likely contributed to the continued slow decline in $\mathrm{PBF}$ in this group and returning to PEEP of $5 \mathrm{~cm} \mathrm{H}_{2} \mathrm{O}$ (instead of $8 \mathrm{~cm} \mathrm{H}_{2} \mathrm{O}$ ) may have been prudent. Although the inequality of $P_{\text {aw }}$ strategy does not allow direct comparison of PBF between the PEEP $_{\text {adj }}$ group, and previous observations of a delayed recovery of PBF after a stepwise $P_{\text {aw }}$ recruitment strategy during HFOV (7), differences between effect of HFJV and HFOV are plausible theoretically. Lung volume recruitment is most often 
achieved during HFOV by incrementing and decrementing $P_{\mathrm{aw}}$. Although incrementing and decrementing PEEP during HFJV may also alter $P_{\text {aw }}$, the subject spends substantially longer at PEEP than at the PIP, with potential for less negative impact on PBF. A direct comparison of HFJV and HFOV in a controlled setting using clinically defined and comparable recruitment strategies is warranted to determine the extent and duration of their impact on pulmonary hemodynamics.

Lung inflammation is a prelude to lung injury. We examined inflammatory markers that we anticipated would be increased at $120 \mathrm{~min}$ in response to lung injury (13,24-26). There was a clear increase in lung injury across the range of inflammatory markers for the $\mathrm{PEEP}_{\text {const }}$ group, compared with the UVCs and for the $\mathrm{PEEP}_{\text {const }}$ group compared with $\mathrm{PEEP}_{\text {adj }}$. These findings support our hypothesis regarding reduced lung injury with PEEP recruitment of the lung during HFJV.

MPO activity has been shown to correlate with IL6 expression (16), but our results did not show a clear relationship between these variables. The MPO activity was not different between the groups, despite a trend for an increase in the ventilated groups. It is possible that this is a result of maternal anesthesia, and this finding in itself warrants further investigation. It is also possible that a Type II statistical error as a result of the small group sizes prohibited a demonstrable difference between the groups.

There are a number of limitations to our study. We wanted to examine the physiological changes associated with each PEEP alteration and required at least $10 \mathrm{~min}$ to accommodate and document any changes. Consequently, the adjusted PEEP protocol that we studied does not reflect standard clinical practice given that the 60-min period for increasing and decreasing PEEP is considerably longer than optimally used in a clinical setting. This period of time at a higher PEEP may have attenuated our lung injury results and potentially masked significant differences between the ventilated groups. Second, surfactant was administered to the lambs before the commencement of ventilation. This practice may not be achieved routinely in a clinical setting. However, our goal was to isolate the effect of PEEP and standardize and optimize all other aspects of care. Third, the lambs in our study were anesthetized and underwent an invasive surgical procedure. The hemodynamic effects of anesthesia combined with the physical impact of instrumentation on lung inflation are likely to impact physiological outcomes. Finally, the flowmeter used for measuring $V_{\mathrm{T}}$ slightly overestimates tidal volume at 7 $\mathrm{Hz}$ (27). However, as HFJV frequency was constant throughout the study, we would not expect this to affect comparisons between the ventilatory groups.

In conclusion, adjusted PEEP during HFJV improves oxygenation and lung compliance and reduces ventilator requirements despite reducing pulmonary perfusion. The majority of markers of injury were higher when PEEP was constant during HFJV. Evaluation of PEEP recruitment maneuvers in human patients is indicated to explore the efficacy of the technique in the target patient population.

Acknowledgments. Surfactant was donated by Abbott Australia. The Life Pulse High-Frequency Ventilators were sup- plied on long-term loan by Bunnell Incorporated. We would like to express our sincere appreciation to the members of the Ovine Research Group for technical assistance and JRL Hall and Co. for provision and early antenatal care of the ewes.

\section{REFERENCES}

1. Jobe AH, Bancalari E 2001 Bronchopulmonary dysplasia. Am J Respir Crit Care Med 163:1723-1729

2. Jobe AJ 1999 The new BPD: an arrest of lung development. Pediatr Res 46:641-646

3. Jobe AH, Ikegami M 1998 Mechanisms initiating lung injury in the preterm. Early Hum Dev 53:81-94

4. Keszler M, Modanlou H, Brudno D, Clark F, Cohen R, Ryan R, Kaneta M, Davis J 1997 Multicenter controlled clinical trial of high-frequency jet ventilation in preterm infants with uncomplicated respiratory distress syndrome. Pediatrics 100:593-599

5. Wiswell T, Graziani LJ, Kornhauser MS, Cullen J, Merton DA, McKee L, Spitzer AR 1996 High-frequency jet ventilation in the early management of respiratory distress syndrome is associated with a greater risk for adverse outcomes. Pediatrics 98:1035-1043

6. Wiswell TE, Graziani LJ, Kornhauser MS, Stanley C, Merton DA, McKee L, Spitzer AR 1996 Effects of hypocarbia on the development of cystic periventricular leukomalacia in premature infants treated with high-frequency jet ventilation. Pediatrics 98:918-924

7. Polglase GR, Moss TJ, Nitsos I, Allison BJ, Pillow JJ, Hooper SB 2008 Differential effect of recruitment manoeuvres on pulmonary blood flow and oxygenation during HFOV in preterm lambs. J Appl Physiol 105:603-610

8. Polglase GR, Morley CJ, Crossley KJ, Dargaville P, Harding R, Morgan DL, Hooper SB 2005 Positive end-expiratory pressure differentially alters pulmonary hemodynamics and oxygenation in ventilated, very premature lambs. J Appl Physiol 99:1453-1461

9. Courtney SE, Asselin JM 2006 High-frequency jet and oscillatory ventilation for neonates: which strategy and when? Respir Care Clin N Am 12:453-467

10. Polglase GR, Wallace MJ, Grant DA, Hooper SB 2004 Influence of fetal breathing movements on pulmonary hemodynamics in fetal sheep. Pediatr Res 56:932-938

11. Jobe AH, Polk D, Ikegami M, Newnham J, Sly P, Kohen R, Kelly R 1993 Lung responses to ultrasound-guided fetal treatments with corticosteroids in preterm lambs. J Appl Physiol 75:2099-2105

12. Smeed J, Watkins C, Rhind S, Hopkins J 2007 Differential cytokine gene expression profiles in the three pathological forms of sheep paratuberculosis. BMC Vet Res 3:18

13. Wallace MJ, Probyn M, Zahra V, Crossley K, Cole T, Davis P, Morley C, Hooper S 2009 Early biomarkers and potential mediators of ventilation-induced lung injury in very preterm lambs. Respir Res 10:19

14. Van Harmelen V, Ariapart P, Hoffstedt J, Lundkvist I, Bringman S, Arner P 2000 Increased adipose angiotensinogen gene expression in human obesity. Obes Res 8:337-341

15. Livak KJ, Schmittgen T 2001 Analysis of relative gene expression data using real-time quantitative PCR and the 2(-Delta Delta C(T)) method. Methods 25:402-408

16. Faith M, Sukumaran A, Pulimood A, Jacob M 2008 How reliable an indicator of inflammation is myeloperoxidase activity? Clin Chim Acta 396:23-25

17. McCabe A, Dowhy M, Holm B, Glick P 2001 Myeloperoxidase activity as a lung injury marker in the lamb model of congenital diaphragmatic hernia. J Pediatr Surg 36:334-337

18. Keszler M 2006 High frequency jet ventilation. In: Donn SM, Sinha SK (eds) Manual of Neonatal Respiratory Care. Mosby Elsevier, Philadelphia, pp 232-233

19. Groeneveld AB, Schneider AJ 2008 The relationship between arterial $\mathrm{PO}_{2}$ and mixed venous $\mathrm{PO}_{2}$ in response to changes in positive end-expiratory pressure in ventilated patients. Anaesthesia 63:488-494

20. Trachsel D, McCrindle BW, Nakagawa S, Bohn D 2005 Oxygenation index predicts outcome in children with acute hypoxemic respiratory failure. Am J Respir Crit Care Med 172:206-211

21. Keszler M, Durand D 2001 High frequency ventilation. Past, present and future. Clin Perinatol 28:579-607

22. Sherry KM, Feneck R, Normandale J 1988 Thermodilution cardiac output measurements during conventional and high frequency ventilation. J Cardiothorac Anesth 2:320-325

23. Crossley KJ, Morley C, Allison B, Polglase G, Dargaville P, Harding R, Hooper S 2007 Blood gases and pulmonary blood flow during resuscitation of very preterm lambs treated with antenatal betamethasone and/or Curosurf: effect of positive end-expiratory pressure. Pediatr Res 62:37-42

24. Ikegami M, Jobe AH 2002 Postnatal lung inflammation increased by ventilation of preterm lambs exposed antenatally to Escherichia coli endotoxin. Pediatr Res 52:356-362

25. Naik AS, Kallapur SG, Bachurski CJ, Jobe AH, Michna J, Kramer BW, Ikegami M 2001 Effects of ventilation with different positive end-expiratory pressures on cytokine expression in the preterm lamb lung. Am J Respir Crit Care Med 164:494-498

26. Merritt TA, Cochrane C, Holcombe K, Bohl B, Hallman M, Strayer D, Edwards D, Gluck L 1983 Elastase and alpha 1-proteinase inhibitor activity in the tracheal aspirates during respiratory distress syndrome. Role of inflammation in the pathogenesis of bronchopulmonary dysplasia. J Clin Invest 72:656-666

27. Scalfaro P, Pillow JJ, Sly PD, Cotting J 2001 Reliable tidal volume estimates at the airway opening with an infant monitor during high-frequency oscillatory ventilation. Crit Care Med 29:1925-1930 